\title{
Complicated mechanism for axial elongation in eyes with pathologic myopia accompanying scleral thinning and deformity
}

\author{
Kyoko Ohno-Matsui
}

Received: 21 January 2013 / Accepted: 23 January 2013 / Published online: 10 February 2013

(C) Springer-Verlag Berlin Heidelberg 2013

\section{Dear Editor}

Thank you very much for your interest concerning our recent paper reporting the changes of axial length in eyes of adults with pathologic myopia [1]. This study relates to our earlier study which examined the long-term change of axial length in eyes with pathologic myopia by using A-mode echography [2]. In that study, older individuals with posterior staphyloma were more susceptible to having a larger increase in the axial length, and we considered that a progression of posterior staphyloma with increasing age should be regarded as a key factor for the continuous increase of axial length in adults with high myopia [2]. As you suggested, peripheral hyperopia has been considered to be a cause of myopia progression. However, it is not clear whether axial length increase is regulated by the same mechanism between eyes with mild to moderate myopia and eyes with extreme myopia accompanied by scleral deformity and thinning.

In fact, the patients in our study were extremely myopic; the mean axial length at the onset of the study was $29.35 \pm$ $1.80 \mathrm{~mm}$. In such extremely myopic cases, the sclera becomes very thin and deformed [3, 4]. Recently, we measured the scleral thickness of eyes with pathologic myopia (mean axial length; $29.9 \mathrm{~mm}$ ) by using swept-source OCT, and found that the mean subfoveal scleral thickness of these patients was as thin as $227.9 \pm 82.0 \mu \mathrm{m}$, with a minimum value of $80 \mu \mathrm{m}$ [3]. In $32.7 \%$ of the patients, the curvature of the posterior eye segment was totally irregular and not spherical at all. It is doubtful whether peripheral hyperopia still plays some role in an expansion of sclera in such extremely myopic eyes. In addition to the scleral thinning and deformity, various other factors like myopic chorioretinal atrophy seem to affect the scleral contour in eyes with pathologic myopia. We recently found that a sclera was posteriorly dislocated in the area of patchy chorioretinal atrophy by developing intrachoroidal cavitation in the macula [5]. Thus, the globe expansion in extremely myopic eyes with deformed sclera is not simply explained by defocus theory.

I consider that peripheral hyperopia theory might be more important in less myopic patients than in our patients in the present study. In our patients with extreme myopia with thin and deformed sclera, I think that peripheral hyperopia theory has less impact on the increase of axial length. However, further studies are necessary to confirm this.

\section{References}

1. Saka N, Moriyama M, Shimada N, Nagaoka N, Fukuda K, Hayashi K, Yoshida T, Tokoro T, Ohno-Matsui K (2012) Changes of axial length measured by IOL master during 2 years in eyes of adults with pathologic myopia. Graefes Arch Clin Exp Ophthalmol Jun 8 [Epub ahead of print]

2. Saka N, Ohno-Matsui K, Shimada N, Sueyoshi S, Nagaoka N, Hayashi W, Hayashi K, Moriyama M, Kojima A, Yasuzumi K, Yoshida T, Tokoro T, Mochizuki M (2010) Long-term changes in axial length in adult eyes with pathologic myopia. Am J Ophthalmol 150:562-568

3. Ohno-Matsui K, Akiba M, Modegi T, Tomita M, Ishibashi T, Tokoro T, Moriyama M (2012) Association between shape of sclera and myopic retinochoroidal lesions in patients with pathologic myopia. Invest Ophthalmol Vis Sci 53(10):6046-6061

4. Moriyama M, Ohno-Matsui K, Hayashi K, Shimada N, Yoshida T, Tokoro T, Morita I (2011) Topographical analyses of shape of eyes with pathologic myopia by high-resolution three dimensional magnetic resonance imaging. Ophthalmology 118:1626-1637

5. Ohno-Matsui K, Akiba M, Moriyama M, Ishibashi T, Hirakata A, Tokoro T (2012) Intrachoroidal cavitation in macular area of eyes with pathologic myopia. Am J Ophthalmol 154:382-393
K. Ohno-Matsui $(\bowtie)$

Department of Ophthalmology and Visual Science, Tokyo Medical and Dental University, 1-5-45 Yushima,

Bunkyo-ku, Tokyo 1338519, Japan

e-mail: k.ohno.oph@tmd.ac.jp 